\title{
Moonstruck.......Did a woman land on the Moon?
}

By Helen Schell

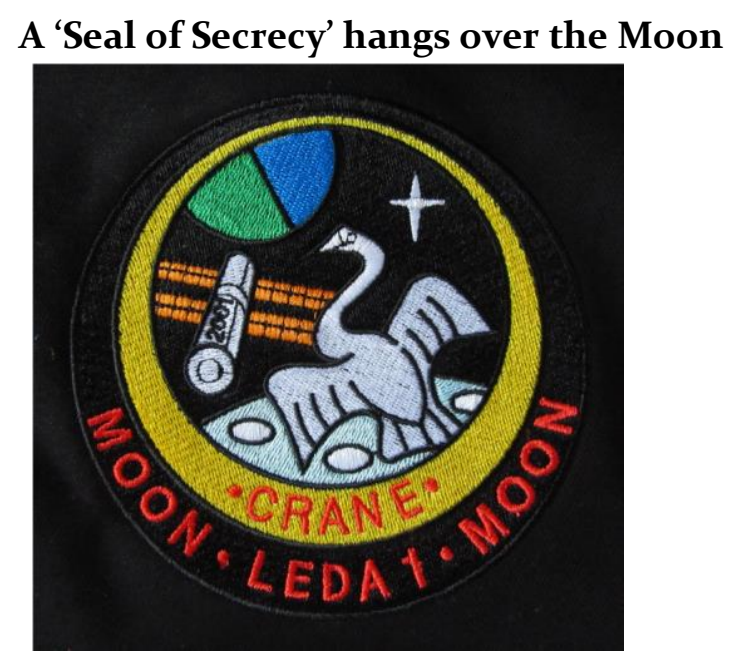

Female Astronaut, Jeanne J Crane (known as JJ), born in Philadelphia 1963 and was part of the 'Woman in Space Program'. She disappeared from NASA records in 2001. Since then, information snippets, rumours, and unverified sources have claimed a female astronaut was sent on a mission to the Moon in August 2001. This classified mission was brought about by a bonus payment into the NASA budget from newly elected President George W Bush Jr, with the aim of making his mark in space history. There was the additional agenda to claim mineral rights to the Moon before other fast developing international space agencies could get there. The US government set up a committee for symbolic activities for the first female astronaut to set foot on the Moon. Part of their remit, was to design an iconic flag for the Moon, which Jeanne Crane would plant as a symbol of a new era of lunar exploration and to further colonisation plans.

Space Shuttles, on 5 missions, from February to August 2001, ferried secret components for a lunar module to the International Space Station where the capsule was constructed by astronauts under the supervision of engineers on Earth. Due to budget constraints, the module was very small and designed to carry one petite member of the astronaut community. Jeanne J Crane was only $4 \mathrm{ft}$ nin and very slight in stature, and this physical fact along with her exceptional career both in the American air-force and the space program made her the prime candidate for the next human to set foot on the Moon. It was regarded 
that selecting a woman would also make the media coverage more sensational and dramatic, adding to historical merit.

The secrecy surrounding the mission, significantly named 'Leda 1', was deemed vital due to the experimental design of the lunar lander which was named 'The Swan' because of its unusual design, (no official diagrams or images exist, so we can only surmise what its appearance was like). Rumour has it that Jeanne Crane did make it to the Moon on August 15, 2001, but never left due to the failure of the lunar lander boosters on take-off, and her remains lie there to this day. Somewhere in the Sea of Serenity (near to the crater Posidonius situated on the northeast rim of the mare), lies her body and the wreckage of this catastrophic mission. This was quickly covered up by the hard landing, on the site of a redundant lunar observation satellite. There is no explanation as to how or why it may have failed, but probably due to the experimental nature of the spaceship and the limited budget, and possibly affected by the gravitational anomalies (mascons) in the Sea of Serenity. These lunar mascons alter the local gravity in certain regions around the Moon and are unstable on a timescale of months or years.

It is understood, that space scientists thought this mission should not be hidden or stricken from the records, but the events of September $11^{\text {th, }}$ 2001, made a cover up inevitable, as this secret mission was considered to be too controversial.

This disastrous mission would never have come to light, if a Norwegian Ph.D. student, studying astrophysics, hadn't accidentally come across references in old documents on an outdated website. He, and his university colleagues, contacted NASA and tried to get this investigated, to see if it was based in fact, but all information immediately disappeared from the internet and no printed records had been kept. No current proof exists except for anecdotal evidence, and officials claim it is a work of pure science fiction. Should this be based on a real episode in lunar exploration, she would be the only woman to have set foot on the Moon, and the only person who has died in space, so she should have a place recorded in history and a rightful memorial erected.

'Philadelphia News Journal report, September 12, 2001: Obituary - NASA Astronaut, Jeanne. J Crane, aged 38, died in a fatal car accident on August 17 ${ }^{\text {th }}$, 20o1'.

\section{Man on the Moon}

\section{Did men ever land on the Moon? Did a woman land on the Moon?}


The Moon is Earth's constant companion and our nearest natural satellite. One can even describe it as a child of our planet as it was once part of Earth. About 4.6 billion years ago an object the size of

Mars, thought to be a small planet, smashed into and merged with proto-Earth. This event knocked off gas and molten debris, which whilst orbiting, through gravitational forces, formed into the Moon. This beautiful sky object is integrally part of our human psyche and legends, and is an important factor in the creation of life on Earth. It slowed down the spin of the Earth and also knocked it off its axis to angles between 22-24 degrees, promoting the development of life on our planet. Its gravity produces our tides twice a day and effects the cycle of our bodies. The Moon used to be much closer and is gradually moving away from our world, one day it will factor in the demise of the life that it helped create.

The Moon has a quarter diameter of Earth, and has one sixth the gravity. It has little atmosphere and no known life, but does have ice at its poles. The same side always faces Earth, but it wobbles whilst in orbit, so we see $59 \%$ of the surface. A Moon day is 27.3 of our days, 13.65 days of daylight (reaching $+111^{\circ}$ ) and 13.65 days of darkness (reaching $-193^{\circ}$ ). We are the only planet in our Solar System with one moon. To date we have discovered that there are at least 175 known moons in our Solar System.

The first organisms that it helped create probably appeared on Earth around 4.3 billion years ago, and then these evolved organisms, in the form of human beings finally made it to the Moon in $1969 . . . . . . . . o r$ did we?

\section{Humans on the Moon}

The first manned mission was the NASA Apollo 11 flight, when Neil Armstrong and Buzz Aldrin were the first humans to set foot on the Moon in 1969. Only 12 American male astronauts have ever been to the Moon. The last human on the Moon was Gene Cernan in 1972. Was this the greatest hoax ever played on humanity? There are many photographs that show abnormalities such as random shadows, lack of dust on vehicles, and the same astronaut images pop up all over the place in NASA documents. There is no doubt that some of these images have been heavily edited, but were they faked? Why have we not been back since 1972? The original Moon missions cost \$25 billion dollars in the 1960's, so the cost is prohibitive. For many decades it has not held much interest due to its hostile conditions and the difficulty in getting there, however, a new space exploration era has begun with commercial companies developing new technologies...... the Moon is a target again for humanity, with plans to build a Moon village. 
There is no doubt that Earthlings set foot on the Moon, there are many myth's and rumours, most of which are nonsense and not founded in real science. It would have been more difficult and expensive to fake missions than to actually go there. It is likely to be a decade before we return and, due to the cost it will be an international venture. The plans to build a colony near the South Pole on the farside of the Moon and a lunar space station (Deep Space Gateway) will be achieved within the next 30 years. The discovery of water on its surface is crucial, as it offers the opportunity to colonise it. Also, the hydrogen component can be used to create rocket fuel for journeys further into space and the oxygen can create air for humans to breathe. Moon based rocket launches would use far less fuel as there is little gravity. Both NASA and ESA have announced they will return humans to the Moon and this being a stepping stone to Mars. This is an international venture which will include all the world's space agencies. 